\title{
Observed Data Containing One Parameter and Chance Error: Evaluation of the Parameter Applying Pythagorean Mean
}

\author{
Dhritikesh Chakrabarty \\ Department of Statistics, Handique Girls' College, Guwahati, Assam, India, \\ dhritikesh.c@rediffmail.com,dhritikeshchakrabarty@gmail.com
}

\begin{abstract}
In order to evaluate the appropriate value of the parameter from observed data containing the parameter itself and chance error, one method has been developed for evaluation of the parameter as the existing statistical methods of estimation in such situation fail in finding out the appropriate value of the parameter. The method developed here is based on the Pythagorean means This paper describes the derivation of this method with one numerical application in evaluating the central tendency of the observed data on each of annual maximum and annual minimum of ambient air temperature at Guwahati.
\end{abstract}

Key words: 1; Observed data 2; parameter 3; chance error 4; Pythagorean mean 5; evaluation of parameter

\section{Introduction:}

There are many situations where observed data

$$
x_{1}, x_{2}, \ldots \ldots \ldots ., x_{n}
$$

are composed of some parameter $\mu$ and chance errors $\varepsilon_{i}$ i.e.

$$
x_{i}=\mu+\varepsilon_{i}, \quad(i=1,2, \ldots \ldots \ldots, n)
$$

[Chakrabarty $(2014 a, 2014 b, 2014 c, 2015 a, 2015 b, 2015 c, 2015 d, 2015 e]$. The existing methods of estimation of $\mu$ namely least squares method, maximum likelihood method, minimum variance unbiased method, method of moment and method of minimum chi-square, [Aldrich (1930), Anders (1999), 
Barnard (1949), Birnbaum (1962), Ivory (1825), Kendall \& Stuart (1977), Lehmann \& Casella George (1998), Lucien (1990), Walker \& Lev (1965)]

provides $\bar{X}$ as estimator of the parameter $\mu$ where $X$ is given by

$$
\bar{X}=\frac{1}{n} \sum_{\mathrm{i}=1}^{\mathrm{n}} x_{i}
$$

It has been shown that this estimator $\bar{X}$ of the parameter $\mu$ suffers from an error $\bar{\varepsilon}$ given by

$$
\varepsilon=\frac{1}{n} \sum_{i=1}^{n} \varepsilon_{i}
$$

which is not zero usually. In other words, none of these methods can provide appropriate value of the parameter $\mu$ [Chakrabarty $(2014 a, 2014 b, 2014 c)]$.

Recently, some studies have been done on determining the true value of the parameter $\mu$ involved in the model described by (1.1) [Chakrabarty $(2014 a, 2014 b, 2014 c, 2015 a, 2015 b, 2015 c, 2015 d$, 2015e , 2015f , 2016a , 2016b) , Bordoloi \& Chakrabarty (2015 , $2015-16$, 2016a , 2016b , 2016c , 2016 - 17)]. In these studies some methods have been developed for determining the true value of the parameter $\mu$ when $\varepsilon_{i}$ occurs due to chance only. One of them is based on computing sequence of interval value of $\mu$ with decreasing length of interval and then to find out the shortest interval value of $\mu$ [Chakrabarty $(2014 a, 2014 b, 2014 c, 2015 d)$, Bordoloi \& Chakrabarty $(2016 a, 2016 b$ ]. The other one is based on stable mid range and median. However, these methods may not be always successful in determining the true value $\mu$ [Chakrabarty (2015b), Bordoloi \& Chakrabarty (2015)]. For this reason, another method has been derived for determining the true value $\mu$ which is based on the convergence of statistic i.e. some function of the available numerical data (Chakrabarty, 2017). However, in some situations, the available data may not be sufficient obtaining the converging point of the statistic considered. In order to determine the true value $\mu$ in such situation, one method has been introduced here. The method is based on the Pythagorean means [Kolmogorov (1930), O'Meara (1989), Riedweg (2005), Cornelli, McKirahan \& Macris (2013), de Carvalho (2016), Chakrabarty (2018b , 2018b)]. This paper describes the derivation of this method and on one numerical application of the method in determining the 
central tendency of each of annual maximum and annual minimum of ambient air temperature at Guwahati.

\section{Method of Determination of Parameter $\mu$ :}

If the observations

$$
x_{1}, x_{2}, \ldots \ldots \ldots ., x_{n}
$$

are composed of some parameter $\mu$ and chance errors then the observations can be expressed as

$$
x_{i}=\mu+\varepsilon_{i} \quad, \quad(i=1,2, \ldots \ldots \ldots, n)
$$

where

(i) $x_{1}, x_{2}, \ldots \ldots \ldots \ldots, x_{n}$ are observed data,

(ii) $\mu$ is the parameter

\& (iii) $\varepsilon_{1}, \varepsilon_{2}, \ldots \ldots \ldots \ldots, \varepsilon_{n}$ are the chance errors associated to

$$
x_{1}, x_{2}, \ldots \ldots \ldots \ldots, x_{n}
$$

respectively which assume positive and negative values in random order.

From Equations described by (2.1),

$$
\sum_{\mathrm{i}=1}^{\mathrm{n}} \mathrm{x}_{\mathrm{i}}=n \mu+\sum_{i=1}^{n} \varepsilon_{i}
$$

which implies

$$
A\left(x_{1}, x_{2}, \ldots . . \ldots . ., x_{n}\right)=\mu+A\left(\varepsilon_{1}, \varepsilon_{2},\right.
$$

where

$$
\begin{aligned}
A\left(x_{1}, x_{2}, \ldots . . . \ldots . ., x_{n}\right) & =\frac{1}{n} \sum_{\mathrm{i}=1}^{\mathrm{n}} x_{\mathrm{i}} \\
\& \quad & A\left(\varepsilon_{1}, \varepsilon_{2}, \ldots . . \ldots \ldots, \varepsilon_{n}\right)=\frac{1}{n} \sum_{i=1}^{n} \varepsilon_{i}
\end{aligned}
$$

Now,

$$
\varepsilon_{1}, \varepsilon_{2}, \ldots \ldots \ldots \ldots, \varepsilon_{n}
$$

being chance errors (i.e. random errors), assume positive and negative values in random order. 
Hence, the series $\left\{U_{n}\right\}$

where

$$
U_{n}=\frac{1}{n} \sum_{i=1}^{n} \varepsilon_{i}
$$

approaches 0 as $n \rightarrow \infty$

Accordingly,

$$
A\left(x_{1}, x_{2}, \ldots . . \ldots \ldots, x_{n}\right)=\frac{1}{n} \sum_{\mathrm{i}=1}^{\mathrm{n}} \mathrm{x}_{\mathrm{i}} \rightarrow \mu \text { as } n \rightarrow \infty
$$

Again, if the observations

$$
x_{1}, x_{2}, \ldots \ldots \ldots ., x_{n}
$$

are composed of some parameter $\mu$ and chance errors then the observations can also be expressed as

$$
x_{i}=\mu . e_{i}, \quad(i=1,2, \ldots \ldots \ldots, n)
$$

where

(i) $x_{1}, x_{2}, \ldots \ldots \ldots \ldots, x_{n}$ are observed data on the variable $X$,

(ii) $\mu$ is the parameter

\& (iii) $e_{1}, e_{2}$, ,$e_{n}$ are the chance errors associated to

$$
x_{1}, x_{2}, \ldots \ldots \ldots ., x_{n}
$$

respectively whose magnitude are pure decimal fraction and greater than 1 occurred in random order.

From equations described by (2.1),

$$
\left(\prod_{i=1}^{n} x_{i}\right)^{1 / n}=\mu \cdot\left(\prod_{i=1}^{n} e_{i}\right)^{1 / n}
$$

which implies

$$
G\left(x_{1}, x_{2}, \ldots . \ldots \ldots ., x_{n}\right)=\mu . G\left(e_{1}, e_{2}, \ldots . \ldots \ldots ., e_{n}\right)
$$

where

$$
\begin{aligned}
G\left(x_{1}, x_{2}, \ldots . . . . . ., x_{n}\right) & =\left(\prod_{i=1}^{n} x_{i}\right)^{1 / n} \\
\& G\left(e_{1}, e_{2}, \ldots . . . . . ., e_{n}\right) & =\left(\prod_{i=1}^{n} e_{i}\right)^{1 / n}
\end{aligned}
$$

Since the magnitude of

$$
e_{1}, e_{2}, \ldots \ldots \ldots \ldots, e_{n}
$$


are pure decimal fraction and greater than 1 occurred in random order,

therefore the series $\left\{V_{n}\right\}$

where

$$
V_{n}=\left(\prod_{i=1}^{n} e_{i}\right)^{1 / n}
$$

approaches 1 as $n \rightarrow \infty$

Accordingly,

$$
G\left(x_{1}, x_{2}, \ldots . . . \ldots, x_{n}\right)=\left(\prod_{i=1}^{n} x_{i}\right)^{1 / n} \rightarrow \mu \text { as } n \rightarrow \infty
$$

\section{Note:}

2.1. From (2.6),

$$
\log G\left(x_{1}, x_{2}, \ldots \ldots \ldots \ldots, x_{n}\right)=\frac{1}{n} \sum_{i=1}^{n} \log x_{i}
$$

which yields,

$$
G\left(x_{1}, x_{2}, \ldots . . \ldots \ldots, x_{n}\right)=\operatorname{antilog}\left\{\frac{1}{n} \sum_{i=1}^{n} \log x_{i}\right\}
$$

This formula can be applied in computing $G\left(x_{1}, x_{2}, \ldots \ldots \ldots ., x_{n}\right)$ since its computation by

$$
G\left(x_{1}, x_{2}, \ldots . . . . . ., x_{n}\right)=\left(\prod_{i=1}^{n} x_{i}\right)^{1 / n}
$$

is too complicated.

2.2. In order to determine the value of $\mu$, it is required to compute the converging values of the two series $\left\{A_{n}\right\} \&\left\{G_{n}\right\}$ where

$$
\begin{gathered}
A_{n}=A\left(x_{1}, x_{2}, \ldots . \ldots \ldots ., x_{n}\right)=\frac{1}{n} \sum_{\mathrm{i}=1}^{\mathrm{n}} \mathrm{x}_{\mathrm{i}} \\
\& G_{n}=G\left(x_{1}, x_{2}, \ldots \ldots \ldots . ., x_{n}\right)=\left(\prod_{i=1}^{n} x_{i}\right)^{1 / n}
\end{gathered}
$$

The common value of them is the value of $\mu$.

2.3. If the series is found to converge but fail to yield a common converging point for the available data then it is to be understood that the data are insufficient for obtaining the value of $\mu$.

2.4. If the series is found either not to converge or to converge to different points then it is to be understood that the errors involved in the data are not only due to chance but also due to some assignable cause(s). Consequently, the data do not follow the model described by the equation (2.1). Accordingly, the value of $\mu$ cannot be determined from the given data in this case. 


\section{Application to Numerical Data:}

Observed data considered here are the data on each of annual maximum \& annual minimum of ambient air temperature, occurred in temperature periodic year (TPR), at Guwahati during1969 $\square 2013$. Application of the method developed here has been shown below in evaluating the central tendency of each of annual maximum \& annual minimum of ambient air temperature at Guwahati from these data.

\subsection{Annual Maximum Temperature at Guwahati:}

The following table shows the observed data on annual maximum of ambient air temperature, occurred in temperature periodic year (TPR), at Guwahati during1969 $\square$ 2013:

Table-3.1.1

Observed Value on Annual Maximum of Ambient Air Temperature (in Degree Celsius)

\begin{tabular}{|c|c|c|c|c|c|}
\hline $\begin{array}{l}\text { TPR No } \\
\quad(i)\end{array}$ & $\begin{array}{c}\text { Observed } \\
\text { Value }\left(x_{i}\right)\end{array}$ & $\begin{array}{c}\text { Date } \\
\text { of occurrence }\end{array}$ & $\begin{array}{l}\text { TPR No } \\
\quad(i)\end{array}$ & $\begin{array}{c}\text { Observed } \\
\text { Value }\left(X_{i}\right)\end{array}$ & $\begin{array}{c}\text { Date } \\
\text { of occurrence }\end{array}$ \\
\hline 1 & 37.1 & 1969, May, 20 & 23 & 37.4 & 1991, July, 20 \\
\hline 2 & 36.6 & 1970, April,01 & 24 & 39.4 & 1992, April, 16 \\
\hline 3 & 36.0 & 1971, March, 27 & 25 & 36.4 & 1993, September, 08 \\
\hline 4 & 35.7 & 1972, July, 14 & 26 & 38.1 & 1994, May, 07 \\
\hline 5 & 39.0 & 1973, April,10 & 27 & 36.3 & 1995, May, 14 \\
\hline 6 & 36.1 & 1974, August, 14 & 28 & 39.9 & 1996, April, 19 \\
\hline 7 & 39.2 & 1975, April, 10 & 29 & 37.4 & 1998, May 21 \\
\hline 8 & 39.0 & 1976, April,17 & 30 & 37.5 & 2000, May, 13 \\
\hline 9 & 35.3 & 1977, August, 14 & 31 & 36.7 & 2001, April,07 \\
\hline 10 & 36.8 & 1978, May, 19 & 32 & 35.7 & 2002, September, 20 \\
\hline 11 & 38.6 & 1979, March, 27 & 33 & 37.4 & 2003, July, 26 \\
\hline 12 & 35.1 & 1980, July, 01 & 34 & 38.0 & 2004, March, 28 \\
\hline 13 & 35.8 & 1981, June, 21 & 35 & 36.6 & 2005, July, 30 \\
\hline 14 & 36.5 & 1982, May, 26 & 36 & 38.0 & 2006, August, 11 \\
\hline 15 & 36.7 & 1983, April, 06 & 37 & 37.3 & 2007, May, 06 \\
\hline 16 & 37.2 & 1984, April, 06 & 38 & 37.3 & 2008, August, 08 \\
\hline 17 & 36.5 & 1985, April,26 & 39 & 38.0 & 2009, May, 23 \\
\hline 18 & 38.4 & 1986, April,03 & 40 & 37.2 & 2010, July, 03 \\
\hline 19 & 37.2 & 1987, May, 19 & 41 & 37.3 & 2011, August, 30 \\
\hline 20 & 36.4 & 1988, August, 03 & 42 & 37.4 & 2012, April,03 \\
\hline 21 & 36.7 & 1989, July, 23 & 43 & 38.8 & 2013, June, 12 \\
\hline 22 & 36.0 & 1990, September, 02 & & & \\
\hline
\end{tabular}


Here the observed values $x_{i}(i=1,2,3$, 43) can be assumed to be composed of a parameter $\mu$ (representing the central tendency of annual maximum) and chance errors.

\section{Determination of Value of $\mu$ (the central tendency of annual maximum)}

The computed values of $A_{n}=A\left(x_{1}, x_{2}, \ldots . \ldots \ldots ., x_{n}\right) \& G_{n}=G\left(x_{1}, x_{2}, \ldots \ldots \ldots ., x_{n}\right)$ have been shown in Table-3.1.2.

In Table-3.1.2, it is found that the values of $A_{n}=A\left(x_{1}, x_{2}, \ldots \ldots \ldots ., x_{n}\right)$ and $G_{n}=G\left(x_{1}, x_{2}\right.$, ,$\left.x_{n}\right)$ are approaching 37.2.

Hence, the true value of the central tendency of annual maximum of the ambient air temperature at Guwahati can be taken as 37.2 Degree Celsius (being the common value of them).

Table-3.1.2

\begin{tabular}{|c|c|c|}
\hline $\begin{array}{c}\text { TPR } \\
\text { No } \\
(n)\end{array}$ & $A_{n}=A\left(x_{1}, x_{2}, \ldots \ldots \ldots, x_{n}\right)$ & $G_{n}=G\left(x_{1}, x_{2}, \ldots \ldots \ldots \ldots, x_{n}\right)$ \\
\hline 1 & 37.1 & 37.100000000000000000000000000001 \\
\hline 2 & 36.85 & 36.849151957677397816492457471162 \\
\hline 3 & 36.56666666666667 & 36.563898828796401481877921649392 \\
\hline 4 & 36.35 & 36.345983740858013867930065117099 \\
\hline 5 & 36.88 & 36.861929466436019045199560948853 \\
\hline 6 & 36.75 & 36.733833524906529592733500969237 \\
\hline 7 & 37.1 & 37.076408237779582297449661223967 \\
\hline 8 & 37.3375 & 37.311570055521037921393145135076 \\
\hline 9 & 37.1111111111111 & 37.082517567449318065559488651693 \\
\hline 10 & 37.08 & 37.054168483041978324085190136495 \\
\hline 11 & 37.21818181818182 & 37.192102443715679881528536182712 \\
\hline 12 & 37.04166666666667 & 37.013097252648824947218023353606 \\
\hline 13 & 36.94615384615385 & 36.918340130784241941575383015056 \\
\hline 14 & 39.75492307692308 & 36.888300330268507049140494882929 \\
\hline 15 & 36.9 & 36.875716972191085058307452585677 \\
\hline 16 & 36.91875 & 36.895901586189937568294003784643 \\
\hline 17 & 36.89411764705882 & 36.872494839717900572818157696334 \\
\hline 18 & 36.977777777777778 & 36.955739386544954474314437641907 \\
\hline 19 & 36.98947368421053 & 36.968555130673424804462730928845 \\
\hline 20 & 36.96 & 36.939917603077075159918808821998 \\
\hline
\end{tabular}


Table-3.1.2 Continued

\begin{tabular}{|c|c|c|}
\hline $\begin{array}{c}\text { TPR } \\
\text { No } \\
(n)\end{array}$ & $A_{n}=A\left(x_{1}, x_{2}, \ldots \ldots \ldots \ldots, x_{n}\right)$ & $G_{n}=G\left(x_{1}, x_{2}, \ldots \ldots \ldots \ldots, x_{n}\right)$ \\
\hline 21 & 36.94761904761905 & 36.928457471495227871573252621182 \\
\hline 22 & 36.90454545454545 & 36.885739991394209779636891882147 \\
\hline 23 & 36.92608695652174 & 36.907951375530228273997704899203 \\
\hline 24 & 37.02916666666667 & 37.008568334146486997509657949442 \\
\hline 25 & 37.004 & 36.984031371155694976981399533444 \\
\hline 26 & 37.04615384615385 & 37.026342595226743557691601271825 \\
\hline 27 & 37.01851851851852 & 36.999183617772609404713638815137 \\
\hline 28 & 37.12142857142857 & 37.099058031246057185229984821213 \\
\hline 29 & 37.13103448275862 & 37.109394916981577631613488308734 \\
\hline 30 & 37.14333333333333 & 37.122349300390835138945562995519 \\
\hline 31 & 37.12903225806452 & 37.108649562396908895644952409924 \\
\hline 32 & 37.084375 & 37.063799115887290185156645453858 \\
\hline 33 & 37.09393939393939 & 37.073942480150612130026293039573 \\
\hline 34 & 37.12058823529412 & 37.10085461802179646288605030756 \\
\hline 35 & 37.10571428571429 & 37.0864498129419154156748278045 \\
\hline 36 & 37.13055555555556 & 37.111527173121534380089866586791 \\
\hline 37 & 37.13513513513514 & 37.116608490052709885185023589966 \\
\hline 38 & 37.13947368421053 & 37.121423011021134475117582568853 \\
\hline 39 & 37.16153846153846 & 37.143694849862191868851959925933 \\
\hline 40 & 37.1625 & 37.145101439431196544614817207745 \\
\hline 41 & 37.16585365853659 & 37.148871788937429088904002963936 \\
\hline 42 & 37.17142857142857 & 37.154831390672328678435909684177 \\
\hline 43 & 37.2093023255814 & 37.192287148576076781925812747586 \\
\hline
\end{tabular}

\subsection{Annual Minimum Temperature at Guwahati:}

The following table (Table-3.2.1) shows the observed data on annual maximum of ambient air temperature, occurred in temperature periodic year (TPR), at Guwahati during $1969 \square 2013$. As earlier, the observed values

$$
x_{i}(i=1,2,3,
$$

can in this case also be assumed to be composed of a parameter $\mu$ (representing the central tendency of annual minimum) and chance errors. 
Table-3.2.1

Observed Value on Annual Minimum of Ambient Air Temperature (in Degree Celsius)

\begin{tabular}{|c|c|c|c|c|c|}
\hline $\begin{array}{l}\text { TPR No } \\
\quad \text { (i) }\end{array}$ & $\begin{array}{c}\text { Observed } \\
\text { Value }\left(x_{i}\right)\end{array}$ & $\begin{array}{c}\text { Date } \\
\text { of occurrence }\end{array}$ & $\begin{array}{l}\text { TPR No } \\
\quad(i)\end{array}$ & $\begin{array}{c}\text { Observed } \\
\text { Value }\left(X_{i}\right)\end{array}$ & $\begin{array}{c}\text { Date } \\
\text { of occurrence }\end{array}$ \\
\hline 1 & 6.6 & 1969, December, 27 & 23 & 5.9 & 1992, January, 05 \\
\hline 2 & 5.9 & 1971, January, 31 & 24 & 8.4 & 1993, February, 23 \\
\hline 3 & 8.2 & 1972, January,21 & 25 & 7.8 & 1993, December, 27 \\
\hline 4 & 5.0 & 1973, February, 03 & 26 & 7.5 & 1995, January, 22 \\
\hline 5 & 6.3 & 1974, February, 07 & 27 & 9.4 & 1996, January, 19 \\
\hline 6 & 7.4 & 1975, January, 19 & 28 & Not Available & Not Available \\
\hline 7 & 6.6 & 1976, January, 22 & 29 & Not Available & Not Available \\
\hline 8 & 6.2 & 1977, January, 30 & 30 & Not Available & Not Available \\
\hline 9 & 7.3 & 1978, January, 12 & 31 & 8.3 & 2000, February, 28 \\
\hline 10 & 6.2 & 1979, January, 09 & 32 & 8.9 & 2001, January, 08 \\
\hline 11 & 6.4 & 1980, February, 08 & 33 & 8.6 & 2002, January, 26 \\
\hline 12 & 7.5 & 1981, January, 10 & 34 & 8.0 & 2003, January, 16 \\
\hline 13 & 8.3 & 1982, February, 07 & 35 & 7.9 & 2004, February, 04 \\
\hline 14 & 4.9 & 1983, January, 06 & 36 & 6.7 & 2004, December, 27 \\
\hline 15 & 6.1 & 1984, January, 30 & 37 & 9.6 & 2006, January, 12 \\
\hline 16 & 7.8 & 1985, January, 19 & 38 & 6.4 & 2007, January, 18 \\
\hline 17 & 8.6 & 1986, January, 20 & 39 & 7.8 & 2008, February, 03 \\
\hline 18 & 7.7 & 1987, January, 05 & 40 & 9.9 & 2009, January, 07 \\
\hline 19 & 9.2 & 1988, January, 01 & 41 & 8.6 & 2010, January , 03 \\
\hline 20 & 6.7 & 1989, January, 14 & 42 & 7.0 & 2011, January, 21 \\
\hline 21 & 8.6 & 1989, December, 31 & 43 & 6.4 & 2012, January, 15 \\
\hline 22 & 7.4 & 1991, January, 20 & 44 & 5.6 & 2013, January, 11 \\
\hline
\end{tabular}

\section{Determination of Value of $\boldsymbol{\mu}$ (the central tendency of annual minimum)}

The computed values of

$$
A_{n}=A\left(x_{1}, x_{2}, \ldots . \ldots \ldots ., x_{n}\right) \text { and } G_{n}=G\left(x_{1}, x_{2}, \ldots . \ldots \ldots, x_{n}\right)
$$

have been shown in Table-3.2.2.

In Table-3.2.2, it is found that the values of

$$
A_{n}=A\left(x_{1}, x_{2}, \ldots \ldots \ldots . ., x_{n}\right) \text { and } G_{n}=G\left(x_{1}, x_{2}, \ldots \ldots \ldots . x_{n}\right)
$$

re not approaching a common value.

Thus, either the data are insufficient to yield the true value of the central tendency of annual minimum of the ambient air temperature at Guwahati or the data do not follow the model described by equation (2.1). 
Table-3.2.2

\begin{tabular}{|c|c|c|}
\hline $\begin{array}{c}\text { TPR } \\
\text { No } \\
(n)\end{array}$ & $\begin{array}{c}\text { Values of } \\
A_{n}=A\left(x_{1}, x_{2}, \ldots \ldots \ldots \ldots, x_{n}\right)\end{array}$ & $\begin{array}{c}\text { Values of } \\
G_{n}=G\left(x_{1}, x_{2}, \ldots \ldots \ldots \ldots, x_{n}\right)\end{array}$ \\
\hline 1 & 6.6 & 6.6000000000000000000000000000002 \\
\hline 2 & 6.6 & 6.2401923047290778184540741626669 \\
\hline 3 & 6.366666666666667 & 6.8349697977658553153553991473341 \\
\hline 4 & 6.825 & 6.3211333313459467749216627042232 \\
\hline 5 & 6.46 & 6.3169010013367452786283625052215 \\
\hline 6 & 6.433333333333333 & 6.4857272185701169855041242093667 \\
\hline 7 & 6.571428571428571 & 6.5019299609413096599434266552134 \\
\hline 8 & 6.575 & 6.4633989337912701904703289281854 \\
\hline 9 & 6.533333333333333 & 6.5514058846887191769812286015146 \\
\hline 10 & 6.61 & 6.5153871170191872914459649178302 \\
\hline 11 & 6.572727272727273 & 6.5048119729138514238168851259175 \\
\hline 12 & 6.558333333333333 & 6.5824407269348502376566800461569 \\
\hline 13 & 6.630769230769231 & 6.7008890789412278622783766593454 \\
\hline 14 & 6.75 & 6.5527362805560146596136072863623 \\
\hline 15 & 6.626666666666667 & 6.5215350514733093207287599447551 \\
\hline 16 & 6.59375 & 6.5949101184036978619969386660223 \\
\hline 17 & 6.664705882352941 & 6.6987014182595463410514031559311 \\
\hline 18 & 6.772222222222222 & 6.7507455267102729305100790423158 \\
\hline 19 & 6.821052631578947 & 6.8616303970395831831869394230887 \\
\hline 20 & 6.94 & 6.8534570444635167207666214239384 \\
\hline 21 & 6.928571428571429 & 6.9279444662370421736229802749321 \\
\hline 22 & 7.004545454545455 & 6.9487332418478471976809533313006 \\
\hline 23 & 7.021739130434783 & 6.8994798638029492332170025993497 \\
\hline 24 & 6.975 & 6.9562840436945652525470112265315 \\
\hline 25 & 7.032 & 6.9882108302873798619833480810597 \\
\hline 26 & 7.061538461538462 & 7.0072334421441164904282182533205 \\
\hline 27 & 7.077777777777778 & 7.0838901531221111364268314501887 \\
\hline 28 & 7.160714285714286 & 7.1240865180443321452583935939618 \\
\hline 32 & 7.220689655172414 & 7.1789729488032751962564480429371 \\
\hline 33 & 7.266666666666667 & 7.2223221258860362445338145542488 \\
\hline 34 & 7.290322580645161 & 7.2461869803895066094818774956424 \\
\hline 35 & 7.309375 & 7.2657752520059477722135734563005 \\
\hline 36 & 7.290909090909091 & 7.247948125913456784586179510479 \\
\hline 37 & 7.358823529411765 & 7.3081081108055937176215071779575 \\
\hline 38 & 7.331428571428571 & 7.2804552217016962246905047234237 \\
\hline 39 & 7.344444444444444 & 7.2944086947827372183189849879502 \\
\hline 40 & 7.413513513513514 & 7.3548715998389568402950960158236 \\
\hline 41 & 7.444736842105263 & 7.8154612929430738975137961946202 \\
\hline 42 & 7.433333333333333 & 7.7934100068228333088588686838578 \\
\hline 43 & 7.4075 & 7.7551256022354259620074788758758 \\
\hline 44 & 7.363414634146341 & 7.6937848209202825772540315655963 \\
\hline
\end{tabular}


Note: Data corresponding to TPR 29, $30 \& 31$ are not available. Therefore, the values of

$$
A_{n}=A\left(x_{1}, x_{2}, \ldots . \ldots \ldots, x_{n}\right) \text { and } G_{n}=G\left(x_{1}, x_{2}, \ldots \ldots \ldots ., x_{n}\right)
$$

could not be computed corresponding these three TPR.

\section{Conclusion:}

The method, developed here, can provide the value of the parameter if the data follow the model described by equation (2.1) and if the data size is sufficiently large for obtaining the common converging point of $A_{n}=A\left(x_{1}, x_{2}, \ldots \ldots \ldots ., x_{n}\right)$ and $G_{n}=G\left(x_{1}, x_{2}, \ldots \ldots \ldots . ., x_{n}\right)$. Conversely, if the common converging point of $A_{n}=A\left(x_{1}, x_{2}, \ldots . \ldots \ldots, x_{n}\right)$ and $G_{n}=G\left(x_{1}, x_{2}\right.$, ,$\left.x_{n}\right)$ is not achieved from the set of data then it implies that either the data do not follow the model described by equation (2.1) or the data size is not sufficient to yield the common converging point.

Regarding the findings obtained on annual maximum and annual minimum of ambient air temperature at Guwahati, the following conclusion can be drawn:

4.1. The central tendency of Annual Maximum of Ambient Air Temperature at Guwahati can be taken as 37.2 Degree Celsius since all the methods applied have yielded the same numerical results and thus the corresponding data can be treated to follow the model described by equation (2.1).

4.2. The central tendency of Annual Minimum of Ambient Air Temperature at Guwahati is not determinable since the methods applied have yielded different numerical results and thus the corresponding data cannot be treated to follow the model described by equation (2.1).

In this connection, it is to be mentioned that the central tendency of each of annual maximum and annual minimum of the ambient air temperature at Guwahati has been evaluated by another method already developed (Chakrabarty , 2017). The findings obtained by that method have been found to be identical with the findings obtained by the method developed here. 


\section{References:}

Anders Hald, On the History of Maximum Likelihood in Relation to Inverse Probability and Least Squares, Statistical Science, Vol. 14, pp. 214 - 222, 1999.

Aldrich John, Fisher's Inverse Probability of 1930, International Statistical Review, Vol. 68, pp. 155 $172,2000$.

Barnard G. A., Statistical Inference, Journal of the Royal Statistical Society, Series B, Vol. 11, pp. 115 149, 1949.

Bordoloi Rinamani Sarmah \& Chakrabarty Dhritikesh, Central Tendency of Annual Extremum of Ambient Air Temperature at Tezpur Based on Midrange and Median, J. Chem. Bio. Phy. Sci. (E- ISSN : 2249 - 1929), Sec. C, 5(4), 4397 - 4410, 2015.

Bordoloi Rinamani Sarmah \& Chakrabarty Dhritikesh, Annual Extremum of Ambient Air Temperature at Dibrugarh: Determination of Central Tendency, J. Chem. Bio. Phy. Sci. (E- ISSN : 2249 - 1929), Sec. D, 6(1), $212-233,2015-16$.

Bordoloi Rinamani Sarmah \& Chakrabarty Dhritikesh, Determination of Parameter from Observation Containing Itself and Chance Error: Central Tendency of Ambient Air Temperature at Tezpur, International Journal of Advanced Research in Science, Engineering and Technology, (ISSN : $2350-$ 0328), 3(1), 1202 - 1213, $2016 a$.

Bordoloi Rinamani Sarmah \& Chakrabarty Dhritikesh, Determination of Parameter from Observation Containing Itself and Chance Error: Central Tendency of Ambient Air Temperature at Dibrugarh, International Journal of Advanced Research in Science, Engineering and Technology, (ISSN : $2350-$ 0328), 3(8), $2488-2500,2016 b$.

Bordoloi Rinamani Sarmah and Chakrabarty Dhritikesh, Confidence Interval of Annual Extremum of Ambient Air Temperature at Guwahati, Journal of Mathematics and Systems Sciences (ISSN : 0975 5454), 12(1-2), 55-62, $2016 c$.

Bordoloi Rinamani Sarmah \& Chakrabarty Dhritikesh, Determination of Parameter from Observation Containing itself and Chance Error: Central Tendency of Annual Extremum of Ambient Air Temperature at Dhubri, J. Chem. Bio. Phy. Sci. (E- ISSN : 2249 - 1929), Sec. C, 7(1), 062 - 070, 2016 - 17.

Birnbaum Allan, On the Foundations of Statistical Inference, Journal of the American Statistical Association, Vol. 57, pp. 269 - 306, 1962.

Chakrabarty Dhritikesh, Determination of Parameter from Observations Composed of Itself and Errors, International Journal of Engineering Science and Innovative Technology, 3(2), (ISSN : 2139 - 5967), $304-311,2014 a$. 
Chakrabarty Dhritikesh, Analysis of Errors Associated to Observations of Measurement Type, International Journal of Electronics and Applied Research (ISSN : 2395 - 0064), 1(1), 15 - 28, $2014 b$.

Chakrabarty Dhritikesh, Observation Composed of a Parameter and Chance Error: An Analytical Method of Determining the Parameter, International Journal of Electronics and Applied Research (ISSN : 2395 0064), 1(2), $20-38,2014 c$.

Chakrabarty Dhritikesh, Observation Consisting of Parameter and Error: Determination of Parameter, Proceedings of the World Congress on Engineering 2015, (WCE 2015, July 1 - 3, 2015, London, U.K.), ISBN: 978-988-14047-0-1, ISSN: 2078-0958 (Print); ISSN: 2078-0966 (Online), Vol. II, 680 - 684, $2015 a$.

Chakrabarty Dhritikesh, Central Tendency of Annual Extremum of Ambient Air Temperature at Guwahati, J. Chem. Bio. Phy. Sci. (E- ISSN : 2249 - 1929), Sec. C, 5(3), 2863 - 2877, $2015 b$.

Chakrabarty Dhritikesh, Central Tendency of Annual Extremum of Ambient Air Temperature at Guwahati Based on Midrange and Median, J. Chem. Bio. Phy. Sci. (E- ISSN : 2249 - 1929), Sec. D, 5(3), $3193-3204,2015 c$.

Chakrabarty Dhritikesh, Observation Composed of a Parameter and Chance Error: Determining the Parameter as Stable Range, International Journal of Electronics and Applied Research (ISSN : 2395 0064), 2(1), $35-47,2015 d$.

Chakrabarty Dhritikesh, A Method of Finding True Value of Parameter from Observation Containing Itself and Chance Error, Indian Journal of Scientific Research and Technology, (E-ISSN: 2321-9262), $3(4), 14-21,2015 e$.

Chakrabarty Dhritikesh, Theoretical Model Modified For Observed Data: Error Estimation Associated To Parameter, International Journal of Electronics and Applied Research (ISSN : 2395 - 0064), 2(2), 29 45, $2015 f$.

Chakrabarty Dhritikesh, Impact of Error Contained in Observed Data on Theoretical Model: Study of Some Important Situations, International Journal of Advanced Research in Science, Engineering and Technology, (ISSN : 2350 - 0328), 3(1), 1255 - 1265, $2016 a$.

Chakrabarty Dhritikesh, Theoretical Model and Model Satisfied by Observed Data: One Pair of Related Variables, International Journal of Advanced Research in Science, Engineering and Technology, (ISSN : 2350 - 0328), 3(2), $1527-1534,2016 b$.

Chakrabarty Dhritikesh, Numerical Data Containing One Parameter and Chance Error: Evaluation of the Parameter by Convergence of Statistic, International Journal of Electronics and Applied Research (ISSN : 2395 - 0064), 4(2), 59 - 73, 2017. 
Chakrabarty Dhritikesh, Derivation of Some Formulations of Average from One Technique of Construction of Mean, American Journal of Mathematical and Computational Sciences, 3(3), 62 - 68, $2018 a$.

Chakrabarty Dhritikesh, One Generalized Definition of Average: Derivation of Formulations of Various Means, Journal of Environmental Science, Computer Science and Engineering \& Technology, Section C, (E-ISSN : $2278-179$ X), 7(3), $212-225,2018 b$.

Cornelli G., McKirahan R. \& Macris C, On Pythagoreanism, Berlin, Walter de Gruyter, 2013.

de Carvalho Miguel, Mean, what do you Mean?, The American Statistician, 70, 764 -776, 2016.

George Marsagilia, Evaluating the Normal Distribution, Journal of Statistical Software, 11(4), 2004.

Ivory, On the Method of Least Squares, Phil. Mag., LXV, 3 - 10, 1825.

Kendall M. G. and Stuart A, Advanced Theory of Statistics, Vol. 1 \& 2, $4^{\text {th }}$ Edition, New York, Hafner Press, 1977.

Kolmogorov Andrey, On the Notion of Mean, Mathematics and Mechanics, 199(1), 144 - 146, 1930.

Lehmann Erich L. \& Casella George (1998): Theory of Point Estimation, 2nd ed. Springer. ISBN 0 - 387 $-98502-6$.

Lucien Le Cam (1990): Maximum likelihood — An introduction, ISI Review, 58 (2), 153 -171.

Michiel ed. Hazewinkel (2001): Normal Distribution, Encyclopedia of Mathematics, Springer, ISBN 978 $-1-55608-010-4$.

Walker Helen M. and Lev J., Statistical Inference, Oxford \& IBH Publishing Company, 1965.

O'Meara Dominic J., Pythagoras Revived: Mathematics and Philosophy in Late Antiquity, ISBN $\underline{0-19-}$ 823913-0, Clarendon Press, Oxford, 1989.

Riedweg Christoph, Pythagoras: his life, teaching, and influence (translated by Steven Rendall in collaboration with Christoph Riedweg and Andreas Schatzmann, Ithaca), ISBN 0-8014-4240-0, Cornell University Press, 2005.

Walker Helen M. and Lev J. (1990): De Moivre on the Law of Normal Probability, In Smith, David Eugene, 1985. A Source Book in Mathematics, Dover, ISBN 0 - 486 - 64690 - 4, 2, 153 -171.

Wlodzimierz Brye (1995): The Normal Distribution: Characterizations with Applications", Springer Verlag, ISBN $0-387-97990-5$. 